\title{
Microbiologic spectrum and susceptibility of isolates in delayed post-cataract surgery endophthalmitis
}

This article was published in the following Dove Press journal:

Clinical Ophthalmology

16 June 2015

Number of times this article has been viewed

\author{
Animesh Jindal' \\ Avinash Pathengay' \\ Subhadra Jalali ${ }^{2}$ \\ Annie Mathai ${ }^{2}$ \\ Rajeev Reddy Pappuru ${ }^{2}$ \\ Raja Narayanan ${ }^{2}$ \\ Jay Chhablani ${ }^{2}$ \\ Savitri Sharma ${ }^{3,4}$ \\ Taraprasad Das ${ }^{2,3}$ \\ Harry W Flynn Jr ${ }^{5}$ \\ 'L V Prasad Eye Institute, GMR \\ Varalakshmi Campus, Visakhapatnam, \\ India; ${ }^{2}$ Srimati Kannuri Santhamma \\ Centre for Vitreoretinal Diseases, \\ LV Prasad Eye Institute, KAR Campus, \\ Hyderabad, India; ${ }^{3} L$ V Prasad Eye \\ Institute, Bhubaneswar Eye Institute, \\ Bhubaneswar, Odisha, India; ${ }^{4}$ haveri \\ Microbiology Centre, LV Prasad Eye \\ Institute, KAR Campus, Hyderabad, \\ India; ${ }^{5}$ Department of Ophthalmology, \\ Bascom Palmer Eye Institute, \\ University of Miami, Miami, FL, USA
}

Correspondence: Avinash Pathengay L V Prasad Eye Institute, GMR Varalakshmi Campus, II-II3/I, Hanumanthawaka Junction, Visakhapatnam 530040, India Tel +9l 89| 39892020 $\mathrm{Fax}+918913984444$ Email avinash@lvpei.org
Abstract: The objective of this study was to evaluate the microbiological spectrum and antimicrobial susceptibility of isolates in delayed post-cataract surgery endophthalmitis. A retrospective review of 33 consecutive patients with culture proven delayed post-cataract surgery endophthalmitis was done from January 2006 to March 2013. There were 22 bacterial and eleven fungal cases. Common isolates were Streptococci (seven cases), coagulase-negative staphylococci (five), Gram-negative bacilli (seven), Nocardia (two), Aspergillus (five), Candida (five). Gram-positive cocci were most susceptible to vancomycin and gatifloxacin $(91.7 \%)$. Gram-negative isolates were most susceptible to ofloxacin (85.7\%). Fungi being slow growing organisms are an important cause of delayed post-cataract surgery endophthalmitis.

Keywords: delayed endophthalmitis, microbiology, antibiotic sensitivity

\section{Introduction}

Endophthalmitis is a serious vision threatening complication of cataract surgery. It can be classified into two broad categories: acute-onset and delayed-onset. According to endophthalmitis vitrectomy study, infection occurring within 6 weeks after cataract surgery was defined as acute-onset and after 6 weeks as delayed-onset. ${ }^{1}$ These two categories differ in their microbiological spectrum. ${ }^{2}$

The purpose of the current study was to investigate the spectrum of organisms causing culture proven delayed post-cataract surgery endophthalmitis and their antimicrobial susceptibilities at our center between 2006 and 2013 and compare it with available western literature.

\section{Methods}

This was a retrospective, non-comparative, consecutive case series. Microbiology records were reviewed of all the culture proven delayed post-cataract surgery endophthalmitis cases treated at L V Prasad Eye Institute, Hyderabad, India between January 2006 and March 2013. The study was approved by the institutional review board and adhered to the guidelines of the Declaration of Helsinki.

Vitreous samples from all patients had been investigated for bacteria and fungus using institutional protocol. Bacterial isolates were identified using Analytical Profile Index system until 2010 and Vitek-2 compact system (bioMérieux, Craponne, France), thereafter. The susceptibility was determined by the Kirby-Bauer disk diffusion method. Fungal species were identified based on their colony and microscopic characteristics. Susceptibilities for fungal isolates were not performed. 


\section{Results}

\section{Microbial spectrum}

A total of 33 isolates from 33 vitreous samples were identified. Isolates included 12 (36.4\%) Gram-positive cocci, one (3.0\%) Gram-positive bacilli, seven (21.2\%) Gram-negative bacteria, two (6.1\%) Nocardia sp., and eleven (33.3\%) fungi (Table 1).

Most common isolates identified were coagulase negative staphylococci, Aspergillus sp. and Candida sp. (5/33, 15.2\% each) followed by Streptococcus pneumoniae (3/33, 9.1\%) and Burkholderia cepacia $(3 / 33,9.1 \%)$.

Onset of endophthalmitis occurred 30 days to 15 years (median 150 days) post-operatively in streptococcal cases, 30 to 168 (median 72) days in coagulase-negative staphylococcal cases, 60 to 157 (median 84) days in Gram-negative cases, and 60 to 365 (median 76) days in fungal cases.

\section{Antimicrobial susceptibility}

Gram-positive cocci were most susceptible to vancomycin and gatifloxacin (91.7\%). Gram-negative isolates were most susceptible to ofloxacin (85.7\%) followed by ceftazidime, ciprofloxacin, gatifloxacin, and moxifloxacin ( $71.4 \%$ each). Susceptibility of Gram-negative organisms to amikacin was $57.1 \%$. These data can be viewed in detail in Table 1 .

\section{Discussion}

The microorganisms in delayed post-cataract surgery endophthalmitis are believed to be less virulent as indicated by its insidious onset and low grade of inflammation. In most of the studies published in the literature, Propionibacterium acnes were most commonly isolated from the vitreous samples of delayed-onset endophthalmitis. ${ }^{2-5}$ In the current study, P. acnes were not isolated from any sample. One of the reasons for this could be that anaerobic culture was not done in all cases. From India, there are mostly case reports on delayed-onset endophthalmitis after cataract surgery, ${ }^{6}$ thus it is not possible to comment on the incidence of $P$. acnes associated delayed post-cataract surgery endophthalmitis in this region. A higher incidence of fungal isolates noted in the current study is consistent with other studies from the same geographic region. ${ }^{2}$ Fungi, being slow growing organisms, are the frequent cause of delayed-onset endophthalmitis. Comparison of microorganisms identified in various delayed-onset post-cataract surgery endophthalmitis studies is given in Table 2.

The antimicrobial susceptibility of the organisms is comparable to that of the same organisms in different clinical settings like acute post-cataract endophthalmitis and post-traumatic

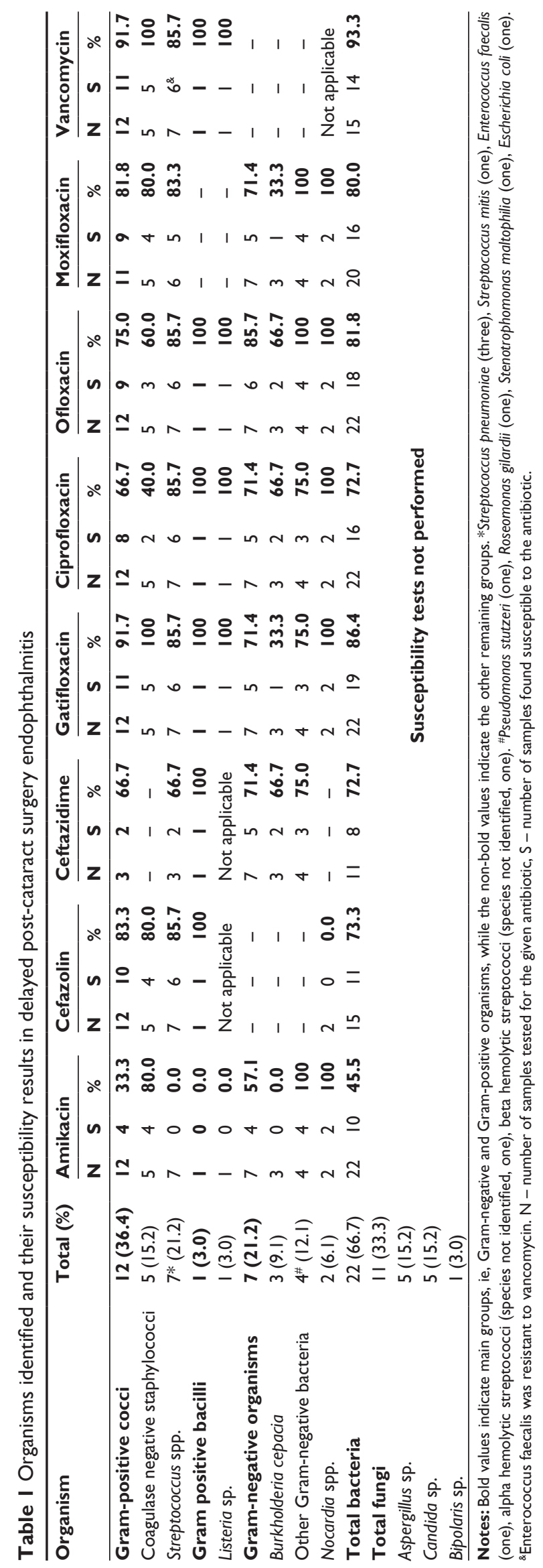


Table 2 Microbiologic comparison of delayed-onset endophthalmitis studies

\begin{tabular}{|c|c|c|c|c|}
\hline & $\begin{array}{l}\text { Current study } \\
(2006-2013)\end{array}$ & $\begin{array}{l}\text { Shirodkar et } \mathrm{al}^{2} \\
(2000-2009)\end{array}$ & $\begin{array}{l}\text { Al-Mezaine et } \mathrm{al}^{3} \\
(1997-2006)\end{array}$ & $\begin{array}{l}\text { Fox et } \mathrm{al}^{5} \\
(1979-1989)\end{array}$ \\
\hline Number of isolates & 33 & 26 & 17 & 19 \\
\hline Propionibacterium acnes & 0 & II & 7 & 12 \\
\hline Fungal species & II & 7 & 3 & 3 \\
\hline Gram-positive species & 13 & 3 & 3 & 4 \\
\hline Gram-negative species & 7 & 3 & I & 0 \\
\hline Mycobacteria & 0 & 2 & 0 & 0 \\
\hline Nocardia species & 2 & 0 & 0 & 0 \\
\hline Mixed & 0 & 0 & 3 & 0 \\
\hline
\end{tabular}

endophthalmitis in the same geographic region. ${ }^{7,8}$ Grampositive organisms are most susceptible to vancomycin and Gram-negative organisms to fluoroquinolones and ceftazidime. Low susceptibility of Gram-negative organisms to amikacin was due to $B$. cepacia being the most common cause and they have been shown to be less susceptible to amikacin as compared to ceftazidime and ciprofloxacin. ${ }^{9}$

This is the first study from India on the antimicrobial spectrum and antimicrobial susceptibility of delayed postcataract surgery endophthalmitis. Less virulent and slow growing organisms like coagulase negative staphylococci and fungi are the most common causative agents of delayedonset endophthalmitis.

\section{Disclosure}

The authors report no conflicts of interest in this work.

\section{References}

1. Johnson MW, Doft BH, Kelsey SF, et al. The Endophthalmitis Vitrectomy Study: relationship between clinical presentation and microbiologic spectrum. Ophthalmology. 1997;104(2):261-272.
2. Shirodkar AR, Pathengay A, Flynn HW Jr, et al. Delayed-versus acuteonset endophthalmitis after cataract surgery. Am J Ophthalmol. 2012; 153(3):391-398.

3. Al-Mezaine HS, Al-Assiri A, Al-Rajhi AA. Incidence, clinical features, causative organisms, and visual outcomes of delayed-onset pseudophakic endophthalmitis. Eur J Ophthalmol. 2009;19(5):804-811.

4. Clark WL, Kaiser PK, Flynn HW Jr, Belfort A, Miller D, Meisler DM. Treatment strategies and visual acuity outcomes in chronic postoperative Propionibacterium acnes endophthalmitis. Ophthalmology. 1999; 106(9):1665-1670.

5. Fox GM, Joondeph BC, Flynn HW Jr, Pflugfelder SC, Roussel TJ. Delayed-onset pseudophakic endophthalmitis. Am J Ophthalmol. 1991; 111(2):163-173.

6. Chaudhry M, Baisakhiya S, Bhatia MS. A rare complication of Nd-YAG capsulotomy: propionibacterium acnes endopthalmitis. Nepal J Ophthalmol. 2011;3(1):80-82.

7. Jindal A, Pathengay A, Mithal K, et al. Microbiologic spectrum and susceptibility of isolates in acute postcataract surgery endophthalmitis: are they same as they were more than a decade ago? Br J Ophthalmol. 2014; 98(3):414-416.

8. Jindal A, Pathengay A, Mithal K, et al. Endophthalmitis after open globe injuries: changes in microbiological spectrum and isolate susceptibility patterns over 14 years. J Ophthalmic Inflamm Infect. 2014;4(1):5.

9. Sachdeva V, Pathengay A, Joseph J, Sharma S, Das T. Burkholderia cepacia endophthalmitis: clinico-microbiologic profile and outcomes. Retina. 2011;31(9):1801-1805.
Clinical Ophthalmology

\section{Publish your work in this journal}

Clinical Ophthalmology is an international, peer-reviewed journal covering all subspecialties within ophthalmology. Key topics include: Optometry; Visual science; Pharmacology and drug therapy in eye diseases; Basic Sciences; Primary and Secondary eye care; Patient Safety and Quality of Care Improvements. This journal is indexed on

Submit your manuscript here: http://www.dovepress.com/clinical-ophthalmology-journal

\section{Dovepress}

PubMed Central and CAS, and is the official journal of The Society of Clinical Ophthalmology (SCO). The manuscript management system is completely online and includes a very quick and fair peer-review system, which is all easy to use. Visit http://www.dovepress.com/ testimonials.php to read real quotes from published authors. 